\title{
Inflammation induced by increased frequency of intermittent hypoxia is attenuated by tempol administration
}

\author{
J. Zhang*, L. Zheng*, J. Cao, B. Chen and D. Jin \\ Department of Respiratory, Tianjin Medical University General Hospital, Tianjin, China
}

\begin{abstract}
The levels of serum inflammatory cytokines and the activation of nuclear factor kappa $\mathrm{B}(\mathrm{NF}-\mathrm{\kappa} \mathrm{B})$ and hypoxia inducible factor- $1 \alpha$ $(\mathrm{HIF}-1 \alpha)$ in heart tissues in response to different frequencies of intermittent hypoxia $(\mathrm{IH})$ and the antioxidant tempol were evaluated. Wistar rats (64 males, 200-220 g) were randomly divided into 6 experimental groups and 2 control groups. Four groups were exposed to $\mathrm{IH} 10,20,30$, or 40 times/h. The other 2 experimental groups were challenged with IH (30 times/h) plus tempol, either beginning on day 0 (IH30T0) or on day 29 (IH30T29). After 6 weeks of challenge, serum levels of tumor necrosis factor (TNF)- $\alpha$, intracellular adhesion molecule (ICAM)-1, and interleukin-10 were measured, and western blot analysis was used to

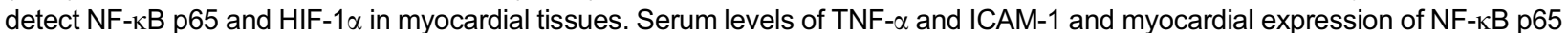
and HIF-1 $\alpha$ were all significantly higher in $\mathrm{IH}$ rats than in controls $(\mathrm{P}<0.001)$. Increased IH frequency resulted in more significant changes. Administration of tempol in IH rats significantly reduced levels of TNF- $\alpha$, ICAM-1, NF- $\mathrm{KB}$ and HIF- $1 \alpha$ compared with the non-tempol-treated group $(\mathrm{F}=16.936, \mathrm{P}<0.001)$. IH induced an inflammatory response in a frequency-dependent manner. Additionally, HIF- $1 \alpha$ and NF-kB were increased following $\mathrm{IH}$ administration. Importantly, tempol treatment attenuated this effect.
\end{abstract}

Key words: Obstructive sleep apnea; Intermittent hypoxia; Inflammation; Nuclear factor kappa B; Antioxidant

\section{Introduction}

Sleep apnea is a common medical condition, primarily caused by complete or partial pharyngeal obstruction and characterized by the repeated cessation of breathing while asleep. The disorder is commonly accompanied by hypoxia, sleep arousal, and hemodynamic changes (1). Persistent recurrence of these conditions can lead to a number of deleterious effects, ranging from sleepiness, fatigue, and poor neurocognitive performance during the day to more severe symptoms, including cardiovascular disease, cerebrovascular disease, and multiple organ injury. Obstructive sleep apnea (OSA) is the most common form of the disorder, and intermittent hypoxia $(\mathrm{IH}$; intermittent periods of oxygen saturation below $90 \%$ ) is a key driver of the pathophysiology of this disease. The harmful effects of IH have been compared with those resulting from ischemia-reperfusion injury, and are thought to be caused by increased endothelial cell dysfunction and inflammation. Importantly, OSA is considered a chronic low-grade inflammatory disease $(2,3)$ and a growing body of evidence links OSA with the development and progression of cardiovascular disease (CAD). Treatment of OSA with continuous positive airway pressure in symptomatic patients without known CAD has been shown to decrease morbidity and mortality associated with cardiovascular events (4). The pathophysiology underlying the association between OSA and CAD is not fully established, but several mechanisms have been proposed, including hyperactive sympathetic drive, vascular inflammation, oxidative stress, endothelial damage, and metabolic deregulation (5).

Previous studies have shown that $\mathrm{IH}$ during sleep results in the increased production of reactive oxygen species (ROS) in response to oxidative stress activation. ROS, including superoxide anion $\left(\mathrm{O}_{2}{ }^{\bullet-}\right)$, hydroxyl radical $\left(\mathrm{OH}^{-}\right)$, and peroxynitrite $\left(\mathrm{ONOO}^{-}\right)$, are second messengers capable of activating and regulating nuclear factor kappa B (NF-kB), hypoxia inducible factor-1 alpha (HIF$1 \alpha$ ), and activator protein-1 (AP-1), transcription factors that regulate genes involved in inflammation and adhesion (6). Although these events set into motion an inflammatory cascade, it is unclear whether the frequency of $\mathrm{IH}$ influences the activation and release of inflammatory and adhesive factors.

Correspondence: Jie Cao: <caojiemedsci@163.com>.

${ }^{*}$ These authors contributed equally to this study.

Received December 18, 2014. Accepted June 26, 2015. First published online September 18, 2015. 


\section{Material and Methods}

\section{Animals}

A total of 64 male Wistar rats (approximately 8 weeks of age, 200-220 g), acquired from the animal experimental center of the Military Medical Science Academy, Tianjin, China, were used in this study. Rats were housed 4 per cage. At all times except during the actual experimental period, rats were provided food and water ad libitum. All surgical procedures and experimental protocols were approved by the Tianjin Medical University Animal Care and Use Committee.

\section{Intermittent hypoxia challenge}

Rats were randomly assigned to 8 groups containing 8 rats per group. Rats in 4 groups received $\mathrm{IH} 10(\mathrm{IH} 10)$, 20 (IH20), 30 (IH30), or $40(\mathrm{IH} 40)$ times per hour, respectively. Tempol (STBB3145, Sigma, USA) was freshly prepared each day and was administered by intraperitoneal injection at $100 \mathrm{mg} / \mathrm{kg}$ before each $\mathrm{IH}$ challenge (30 times/h) in 2 groups of rats on the first day of challenge until the end of the experimental period (IH30T0) or beginning on day 29 of the procedure (IH30T29). Rats in the last 2 groups received compressed air (SC), or were maintained under normal air conditions (NC).

For $\mathrm{IH}$ exposure, rats were placed in a specialized Plexiglas chamber $\left(30 \times 20 \times 20 \mathrm{~cm}^{3}\right.$, with 4 per cage $)$ and were exposed to IH for $8 \mathrm{~h} /$ day (9:00 am to 5:00 pm) for 7 days/week for 6 consecutive weeks. The chamber was flushed with alternating cycles of pure nitrogen and compressed air. Cycles of $\mathrm{IH}$ lasted for 6, 3, 2, and $1.5 \mathrm{~min}$. The first $30 \mathrm{~s}$ of each cycle was defined as the hypoxia phase; the remaining time for each cycle was set as the re-oxygenation phase. Gas flow was regulated by timer-controlled solenoid valves and an $\mathrm{O}_{2}$ flow meter. During the hypoxia phase, the $\mathrm{O}_{2}$ concentration in the chamber was rapidly decreased to $5 \%$ by adjusting the $\mathrm{N}_{2}$ flow rate. In contrast, the $\mathrm{O}_{2}$ concentration was increased to a maximum of $21 \%$ by rapidly flushing the chamber with compressed air. The chamber of animals in the SC group was continuously flushed with compressed air or any special treatment. Supplementary Table S1 provides specific details of the $\mathrm{IH}$ challenge.

To confirm hypoxia following $\mathrm{IH}$ exposure, the blood gas tension of 2 rats per group was measured. Each rat was anesthetized with $25 \%$ urethane $(4 \mathrm{~mL} / \mathrm{kg})$, and arterial lines were surgically inserted into the right common carotid artery. The line was heparinized, and it exited the cage through a small aperture. We measured arterial blood gases at different time points in the hypoxia cycle after the rats had been allowed to adapt to the hypoxic conditions for at least $10 \mathrm{~min}$. Minimum partial pressure of oxygen $\left(\mathrm{PO}_{2}\right)$ and maximum partial pressure of carbon dioxide $\left(\mathrm{PCO}_{2}\right)$ were measured in 3 consecutive hypoxia cycles. Supplementary Figure $\mathrm{S} 1$ shows changes of $\mathrm{PO}_{2}$ in response to chamber oxygen concentration.
Analysis confirmed that oxygenation profiles in our rat model system mimicked those in patients with OSA.

\section{Animal anatomy and sample preparation}

After 6 weeks of challenge, all animals were anesthetized with $3 \%$ pentobarbital $(30 \mathrm{mg} / \mathrm{kg}$ ), and an arterial blood sample was obtained from the right femoral artery. Serum was isolated and frozen at $-80^{\circ} \mathrm{C}$. Residual blood was cleaned, and animals were weighed. Next, small $(1 \mathrm{~cm} \times 0.5 \mathrm{~cm})$ sections of tissue were excised from the right ventricle of the heart, snap frozen in liquid nitrogen, and stored at $-80^{\circ} \mathrm{C}$. On the day of analysis, frozen pericardium was thawed at $4^{\circ} \mathrm{C}$ and then at room temperature. Once fully thawed, samples were homogenized on ice. The homogenate was centrifuged (Sorvall Legend RT; Germany) at $4^{\circ} \mathrm{C}$ at $3000 \mathrm{~g}$ for $10 \mathrm{~min}$, and the supernatant was saved for a future experiment.

\section{Enzyme-linked immunosorbent assay (ELISA)}

Serum levels of tumor necrosis factor (TNF)- $\alpha$, intracellular adhesion molecule (ICAM)-1, and interleukin (IL)-10 were measured using ELISA kits purchased from Ruike Biological Technology Company (China) and were performed according to the manufacturer's protocol. Briefly, $50 \mu \mathrm{L}$ of serum sample was mixed with $50 \mu \mathrm{L}$ of assay diluent, then $100 \mu \mathrm{L}$ of diluent alone (negative control) and $100 \mu \mathrm{L}$ of serially diluted standards (positive control) were added. Solutions were added to a 96-well plate pre-coated with specific monoclonal antibodies to the antigen of interest and incubated at room temperature for $2 \mathrm{~h}$. Following incubation, the plate was washed with $0.01 \mathrm{M}$ phosphate buffered saline 3 times. Next, samples were incubated with appropriate biotinylated antibody and streptavidin-horseradish peroxidase conjugates. A colorimetric reaction was initiated by adding chromogen substrate and it was stopped by the addition of $1 \mathrm{~N}$ $\mathrm{H}_{2} \mathrm{SO}_{4}$ solution. Wells containing substrate alone and stop solution alone were included as controls. Absorbance was measured at $450 \mathrm{~nm}$ using a microplate reader (Labsystems Multiskan, USA). The mean readings of blank wells were subtracted from wells with sample to determine the final value. Standard curves were generated to calculate the concentration of each antigen.

\section{Western blot analysis}

We performed western blot analysis to determine the levels of phosphorylated NF-kB p65 and HIF- $1 \alpha$ in the harvested heart tissue. Nuclear fractions were obtained from myocardial tissues using cellular fractionation reagents from Beyotime Inc. (China). Protein concentrations were determined using a bicinchoninic acid (BCA) protein assay kit (Bomaide Inc., China). Protein markers were purchased from Fermentas (China). Myocardial cell nuclear extracts $(10 \mu \mathrm{g}$ of protein) were run on sodium dodecyl sulfate (SDS)-polyacrylamide gradient gels. Protein samples were separated by electrophoresis and 
transferred to nitrocellulose membranes. Membranes were blocked with $5 \%$ non-fat milk in tris-buffered saline for $1 \mathrm{~h}$ and then incubated with anti-phosphorylated NF- $\mathrm{KB}$ p65 or anti-HIF-1 $\alpha$ rabbit polyclonal antibody (1:200 dilution; Santa Cruz Biotechnology; USA) overnight at $4^{\circ} \mathrm{C}$. Membranes were washed with tris-buffered saline and then incubated with horseradish peroxidaseconjugated anti-rabbit IgG secondary antibody (Boster Inc., China) for $1 \mathrm{~h}$ at room temperature. The secondary antibody was diluted 1:5000 in blocking solution. After washing, membranes were incubated with LumiGLO detection solution (Jing-mei Bioscience, China) and exposed to film (Kodak, USA). Membranes were then stripped, blocked, and re-probed with antibodies to detect GAPDH, which was used as a loading control. Films were scanned, and the intensities of protein bands were quantified using Image $\mathrm{J}$ software (National Institutes of Health, USA). The protein expression levels were normalized to levels of GAPDH.

\section{Statistical analysis}

Data are reported as means $\pm S D$. Statistical comparisons between different groups of rats were performed using a general linear model one-way ANOVA and post hoc Tukey's test. A P value $<0.05$ was considered to be statistically significant. All statistical analyses were performed with IBM SPSS Statistics, Version 19.0 (IBM Corp., USA).

\section{Results}

\section{Circulating cytokines}

Supplementary Table S2 summarizes the quantification of circulating cytokine levels. In general, serum levels of circulating cytokines were significantly altered in the four $\mathrm{IH}$ groups compared with either the SC group or the NC group ( $F=9.676,27.318,20.594 ; P<0.001)$. One exception was TNF- $\alpha$, which was not significantly increased in the $\mathrm{IH} 10$ group (Figure 1). This suggested that the induction of a complete inflammatory response in this model required an $\mathrm{IH}$ frequency greater than 10 times $/ \mathrm{h}$. While serum levels of TNF- $\alpha$ (Figure 1A, only in groups $\mathrm{IH} 20, \mathrm{IH} 30$ and $\mathrm{IH} 40$ ) and ICAM-1 (Figure 1B) were increased by $\mathrm{IH}$ challenge (all IH groups), levels of IL-10 (Figure 1C) were decreased in all $\mathrm{IH}$ groups. Importantly, all changes in cytokine levels were dependent on $\mathrm{IH}$ frequency, with the greatest changes observed in groups with a higher frequency of challenge $(\mathrm{IH} 20$ vs $\mathrm{IH} 30$ and IH40). Taken together, these data support a relationship between systemic inflammation and $\mathrm{IH}$.

\section{NF- $\kappa$ B phosphorylation and HIF-1 $\alpha$ expression}

Supplementary Table S2 summarizes the quantification of tissue protein levels. Phosphorylated NF-kB p65 levels in nuclear extracts from myocardial tissues were significantly increased in $\mathrm{IH}$ rats compared with controls
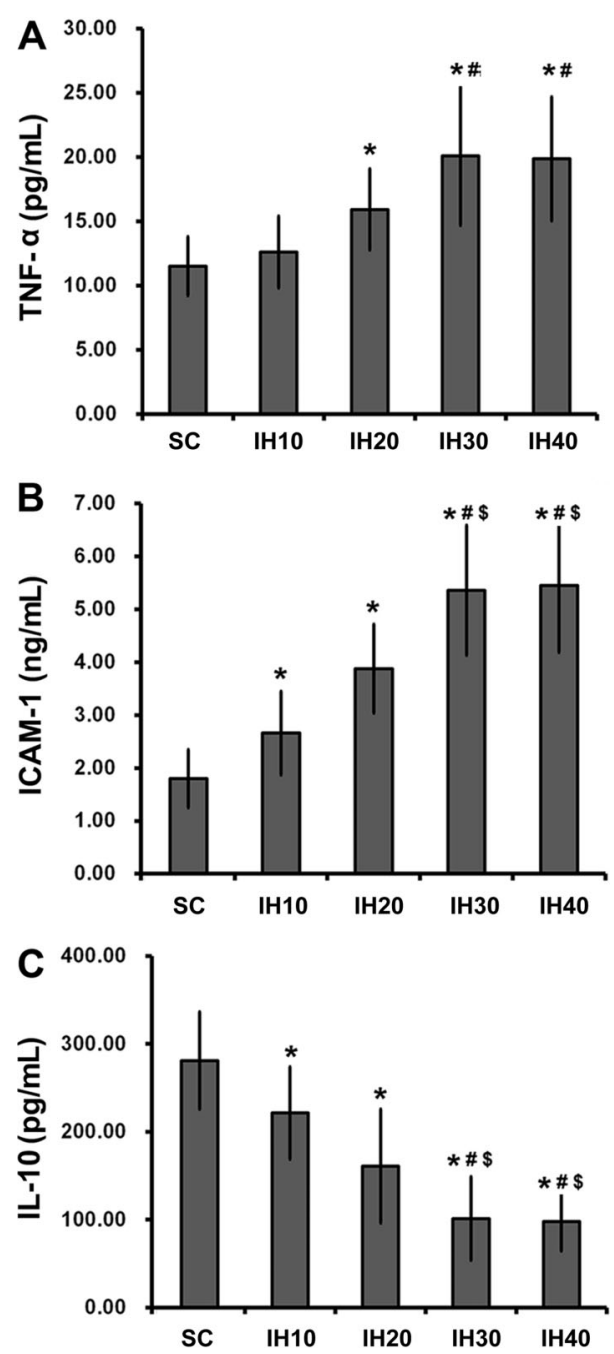

Figure 1. Serum levels of circulating cytokines in groups exposed to different intermittent hypoxia $(\mathrm{IH})$ frequencies. Serum levels of TNF- $\alpha(A)$, ICAM-1 $(B)$, and IL-10 $(C)$ were measured in animals from each group ( $n=8$ each). Data are reported as means $\pm S D$. Rats received compressed air (SC) or $\mathrm{IH}$ at a frequency of 10 (IH10), 20 (IH20), 30 (IH30), and 40 (IH40) times/h. TNF- $\alpha$ : tumor necrosis factor alpha; ICAM-1, intracellular adhesion molecule-1; IL-10, interleukin-10. ${ }^{*} \mathrm{P}<0.05$ vs SC; ${ }^{\#} \mathrm{P}<0.05$ vs IH10; ${ }^{\$} \mathrm{P}<0.05$ vs $\mathrm{IH} 20$ (one-way ANOVA and post hoc Tukey's test).

(Figure 2A and $B ; F=35.089 ; P<0.001)$. The increase in phospho-p65 was frequency-dependent, with more phosphorylated protein detected in rats receiving higher frequency $\mathrm{IH}(\mathrm{P}<0.05$ for $\mathrm{IH} 10$ or $\mathrm{IH} 20$ vs $\mathrm{SC}$ or $\mathrm{NC}$; $\mathrm{P}<0.01$ for $\mathrm{IH} 30$ or $\mathrm{IH} 40$ vs SC or $\mathrm{NC}$ ). Importantly, there was no significant difference in the extent of phospho-p65 induced by $\mathrm{IH} 10$ vs $\mathrm{IH} 20$ or by $\mathrm{IH} 30$ vs $\mathrm{IH} 40(\mathrm{P}>0.05)$.

We also examined changes in HIF- $1 \alpha$ expression in each experimental group. Interestingly, changes in expression of HIF-1 $\alpha$ mirrored the changes observed for phospho-p65. That is, HIF-1 $\alpha$ levels were significantly 
A

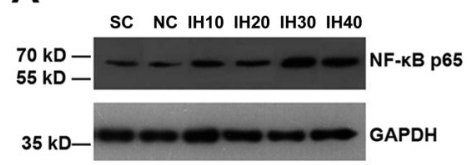

C

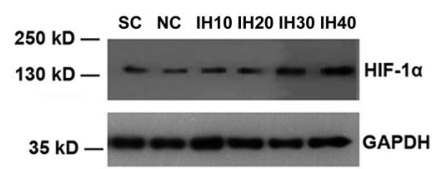

B

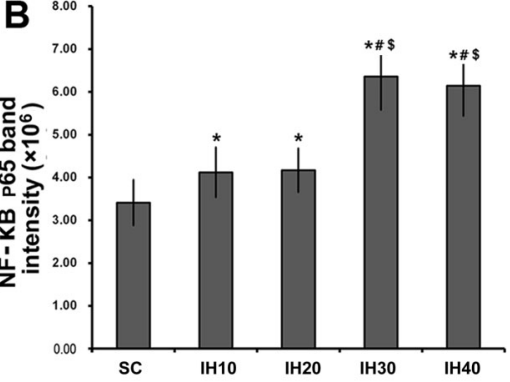

D

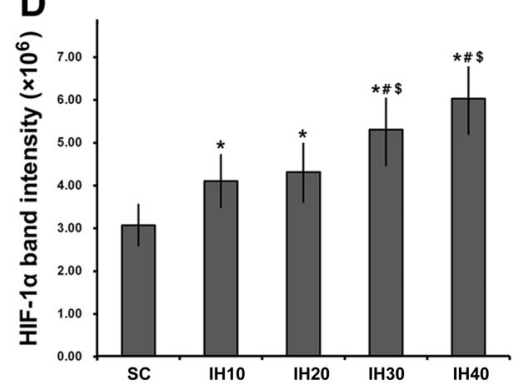

Figure 2. Changes in myocardial expression of phospho-nuclear factor kappa B (NF-kB) and hypoxia inducible factor- $1 \alpha$ (HIF- $1 \alpha$ ) with increasing intermittent hypoxia $(\mathrm{IH})$ frequency. $A$, Western blot analysis of phosphorylated NF-kB p65 in rats challenged with increasing frequencies of $\mathrm{IH}$. GADPH was used as a loading control. $B$, The intensity of phosphorylated NF-KB p65 was normalized to that of GADPH, which was then plotted as means \pm SD. $C$, Western blot analysis of HIF- $1 \alpha$ in rats challenged with increasing frequencies of IH. GADPH was used as a loading control. $D$, The intensity of HIF-1 $\alpha$ was normalized to that of $\mathrm{GADPH}$, which was then plotted as means \pm SD. ${ }^{*} \mathrm{P}<0.05$ vs SC; ${ }^{\#} \mathrm{P}<0.05$ vs $\mathrm{IH} 10 ;{ }^{\$} \mathrm{P}<0.05$ vs $\mathrm{IH} 20$ (one-way ANOVA and post hoc Tukey's test). increased in $\mathrm{IH} 30$ and $\mathrm{IH} 40$ rats compared with controls in a frequency-dependent manner (Figure $2 \mathrm{C}$ and $\mathrm{D}$ ). Heart tissue from rats in groups $\mathrm{IH} 10$ and $\mathrm{IH} 20$ showed similar levels of HIF-1 $\alpha$. Tissue from animals in groups $\mathrm{IH} 30$ and $\mathrm{IH} 40$ were significantly increased compared with group $\mathrm{IH} 10$, while $\mathrm{IH} 30$ was significantly increased compared with group $\mathrm{IH} 20$ but there was no difference between $\mathrm{IH} 10$ and $\mathrm{IH} 20$.

\section{Tempol attenuated the inflammatory effects of intermittent hypoxia}

We next determined whether tempol administration had an effect on $\mathrm{IH}$-mediated inflammation and $\mathrm{NF}-\kappa \mathrm{B}$ activation. The potential effects of tempol were assessed by comparison against $\mathrm{IH} 30$ alone and against the normal oxygen (SC) control group. Quantitative data are summarized in Supplementary Table S3. When administered on day 0 (IH30T0), tempol attenuated the IH30-mediated increase in TNF- $\alpha(P<0.01$; Figure 3A); however, the effect in the IH30T29 group was not significant. Consistent with this, the $\mathrm{IH} 30$-mediated increase in ICAM-1 was also attenuated by tempol administration ( $P<0.05$; Figure 3B). Levels of IL-10 were decreased in the $\mathrm{IH} 30$ group, and this effect was abrogated by tempol whether treatment began on day 0 or on day 29 (Figure $3 C$ ).

Finally, we examined the effect of tempol treatment on myocardial NF- $\mathrm{BB}$ p 65 and $\mathrm{HIF}-1 \alpha$ expression, which was significantly different between $\mathrm{IH}$ and control rats. The $\mathrm{IH} 30-$ mediated increase of $\mathrm{NF}-\mathrm{KB}$ p65 and $\mathrm{HIF}-1 \alpha$ was significantly attenuated in both the IH30T29 and IH30T0 groups (Figure 3D and E). Importantly, earlier tempol treatment (day 0) resulted in a greater benefit compared with treatment beginning on day 29 . Taken together, the data showed that treatment with the antioxidant tempol had the ability to relieve or prevent inflammation resulting from $\mathrm{IH}$.

\section{Discussion}

In the present study, rats receiving $\mathrm{IH}$ with a high frequency displayed more severe inflammation than those receiving low-frequency $\mathrm{IH}$. Moreover, levels of IL-10 were decreased by $\mathrm{IH}$ challenge. Our data indicated that $\mathrm{IH}$ activated myocardial $\mathrm{NF}-\kappa \mathrm{B}$, resulting in systemic inflammation.

$N F-\kappa B$ is a transcription factor involved in cellular responses to various stimuli such as stress or infection. Its activity has been associated with atherosclerosis. Additionally, NF- $\mathrm{KB}$ regulates the expression of a number of genes involved in cell adhesion and inflammation including IL-6, TNF- $\alpha$, E-selectin, vascular cell adhesion molecule-1, ICAM-1, and L-selectin. Importantly, all of these factors were elevated in patients with obstructive sleep apnea syndrome (OSAS) (7-12). Another transcription factor important for inflammatory responses is HIF-1 $\alpha$. Expression of this protein is increased under low oxygen concentrations because it helps both cellular and systemic responses to this type of stress. HIF- $1 \alpha$ is transcriptionally regulated by NF-kB (13). Importantly, hypoxia and inflammation are tightly linked within the cell (14). The results of the present study showed that increased $\mathrm{IH}$ challenge increased HIF-1 $\alpha$ levels. Because HIF- $1 \alpha$ is necessary for adaptive changes of cells in response to hypoxia, the observation of increased HIF- $1 \alpha$ suggested that the cells had adapted to improve survival and energy metabolism by inducing the transcription of a series of genes that 

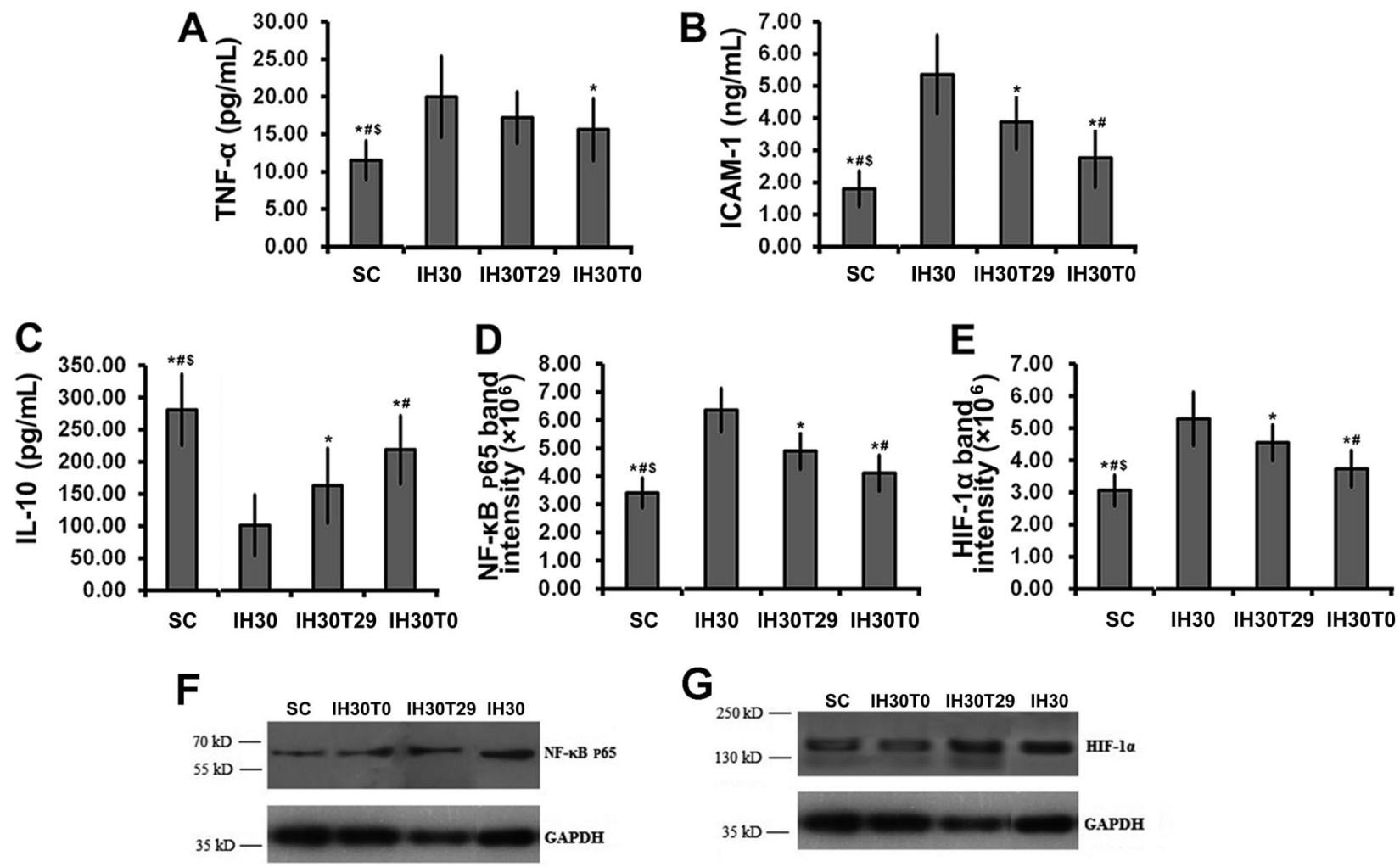

Figure 3. Changes in serum levels of circulating cytokines with tempol treatment. Animals received intermittent hypoxia (IH) 30 times/h as in the $\mathrm{IH} 30$ group. In addition, $1 \mathrm{~mL} / \mathrm{kg}$ of $10 \%$ tempol was administered each time before $\mathrm{IH}$ exposure starting from the first day of treatment (IH30T0 group) or starting from day 29 (IH30T29 group) of the procedure. Serum levels of tumor necrosis factor (TNF)- $\alpha(A)$, intracellular adhesion molecule (ICAM)-1 (B), and interleukin (IL)-10 (C) were measured in the animals $(n=8$ per group) and compared with animals from the compressed air (SC) group. Data are reported as means $\pm S D$. $D$, Myocardial nuclear NF- $\mathrm{KB}$ phosphorylation in different IH30 groups with or without tempol intervention were determined. The quantitative data of $D$ are reported as means \pm SD. $E$, Myocardial hypoxia inducible factor- $1 \alpha(\mathrm{HIF}-1 \alpha)$ protein levels in the IH30 groups with or without tempol intervention were determined. F, Representative Western blot for NF-kB phosphorylation. G, Representative Western blot for HIF-1 $\alpha .{ }^{*} \mathrm{P}<0.05$ vs $\mathrm{IH} 30$; ${ }^{*} \mathrm{P}<0.05$ vs IH30T29; ${ }^{\$} \mathrm{P}<0.05$ vs IH30T0 (one-way ANOVA and post hoc Tukey's test).

participate in angiogenesis, iron metabolism, glucose metabolism, and cell proliferation/survival (15). Nevertheless, increased HIF-1 $\alpha$ indicates that the cells are in a challenged state.

In vitro cell culture models showed that $\mathrm{IH}$ preferentially activates inflammatory pathways instead of the adaptive HIF-1 pathway (16). Moreover, clinical studies have shown that OSAS activates NF- $\mathrm{KB}$, which is inhibited by continuous positive airway pressure therapy $(17,18)$. Other studies have established that NF- $\mathrm{KB}$ activity is increased in myocardial (17) and liver (19) tissues in mice exposed to $\mathrm{IH}$. One important study showed that the level of NF-кB P65 expression in aortic endothelial cells of rats exposed to $\mathrm{IH}$ was significantly higher than in rats exposed to either normal oxygen or to continuous hypoxia. Moreover, the same study showed that cellular stress worsened with increasing levels of $\mathrm{IH}(20)$. This provided evidence that the activation of $\mathrm{NF}-\kappa \mathrm{B}$, to a certain extent, is dependent on the degree of $\mathrm{IH}$. These studies also support the fact that $\mathrm{IH}$ activates NF- $\mathrm{BB}$, which subsequently promotes the expression of inflammatory mediators and adhesion molecules.

Our data showed that the $\mathrm{IH}$-mediated increase in inflammation and NF- $\mathrm{KB}$ was dependent upon the frequency of $\mathrm{IH}$. However, because there was no significant difference between groups $\mathrm{IH} 30$ and $\mathrm{IH} 40$, there is likely a maximum limit of inflammation and NF- $\mathrm{KB}$ activity that can be induced under these conditions. This might be explained by three possibilities. First, with increasing intermittent hypoxic frequency, the period of re-oxygenation is shortened and, at some threshold, this likely results in a situation that is similar to a state of continuous hypoxia. Under these conditions, the adaptive HIF-1 pathway may dominate over NF- $\kappa B$ activation, a finding supported by the work of Yuan et al. (21). Second, high frequency $\mathrm{IH}$ may trigger compensatory mechanisms to protect against excessive inflammatory injuries. NF- $\mathrm{BB}$ signaling is controlled by a negative feedback loop to limit both acute and excessive 
inflammation. Finally, we cannot rule out the possibility that a higher frequency of $\mathrm{IH}$ (greater than 40 times/h) or $\mathrm{IH}$ administered over a long period (longer than 6 weeks) would result in further increases in inflammation and NF- $\mathrm{KB}$ activity. However, the answer to this question would require additional research.

In this study, we observed that $\mathrm{IH}$ challenge of rats lead to decreased expression of circulating IL-10, a critical anti-inflammatory mediator (22), and increased TNF- $\alpha$ and ICAM-1, two molecules involved in inflammatory processes. IL-10 inhibits the nuclear translocation of NF-KB and subsequently decreases levels of TNF- $\alpha$, IL-6, and C-reactive protein, which are all proinflammatory mediators (23). Furthermore, previous studies have shown that IL-10 is decreased in OSA patients (23-25). However, TNF- $\alpha$ activates NF- $\mathrm{BB}$ and MAPK pathways, which have important roles in inflammation and apoptosis (26) and ICAM-1 is involved in the recruitment of macrophages and granulocytes, which may increase the local inflammatory load (27). Thus, our results are in agreement with these studies. This impaired inflammatory response could explain why patients with OSA have a greater risk of cardiovascular disease compared with the general population. However, this is likely a complex biological process, because IL-10 produced by $\mathrm{T}$ lymphocytes was not associated with OSA severity (28). Despite this, our data support the concept that inflammation is a key mediator of $\mathrm{IH}$-induced injury in patients with OSA.

Anti-inflammatory and anti-oxidant therapies are promising options to decrease oxidative stress and inhibit cardiovascular inflammation. A previous study showed that the exogenous administration of the antioxidant $\mathrm{N}$-acetyl-L-cysteine significantly improved $\mathrm{IH}$ mediated myocardial injury in a mouse model (29). Consistent with this, we found that treatment with tempol alleviated some of the $\mathrm{IH}$-induced inflammation in our rat model. Tempol is a nitrogen monoxide molecule with antioxidant properties and has previously been used to successfully treat $\mathrm{IH}$-induced injuries. For example, tempol was shown to improve $\mathrm{IH}$-mediated

\section{References}

1. Jean-Louis G, Zizi F, Brown D, Ogedegbe G, Borer J, McFarlane S. Obstructive sleep apnea and cardiovascular disease: evidence and underlying mechanisms. Minerva Pneumol 2009; 48: 277-293.

2. Morgan BJ. Vascular consequences of intermittent hypoxia. Adv Exp Med Biol 2007; 618: 69-84, doi: 10.1007/978-0387-75434-5.

3. McNicholas WT, Bonsigore MR. Sleep apnoea as an independent risk factor for cardiovascular disease: current evidence, basic mechanisms and research priorities. Eur Respir J 2007; 29: 156-178, doi: 10.1183/09031936. 00027406. skeletal muscle injuries in rats (30). Furthermore, Troncoso et al. (31) showed that tempol decreased the blood pressure of rats exposed to $\mathrm{IH}$ for 14 days, an effect likely mediated by a decrease in serum levels of endothelin-1. These data support the effective use of tempol to combat $\mathrm{IH}$-induced injuries.

Here, we showed that tempol treatment significantly attenuated $\mathrm{IH}$-mediated increase in TNF- $\alpha$, ICAM-1, and $\mathrm{NF}-\kappa \mathrm{B}$. This is consistent with an anti-inflammatory effect of tempol in this rat model. Additionally, we found that early tempol intervention was more beneficial than tempol treatment started at a later time point. Additional studies are required to determine the effects of longer tempol exposure in this model. In addition, we only superficially explored the effects of $\mathrm{IH}$ on the complex inflammation processes. In depth analyses of inflammation are necessary to improve our understanding of the effects of $\mathrm{IH}$ on inflammation.

In conclusion, IH caused both systemic and local cardiovascular inflammation. IH not only increased NF- $\mathrm{KB}$ activity, HIF- $1 \alpha$ and inflammation, but also weakened the anti-inflammatory response, thus upsetting the overall balance of this biological pathway. This could be a major underlying problem in patients with OSA. Moreover, treatment with antioxidants, such as tempol, may be therapeutically beneficial for the treatment or prevention of OSAS-related cardiovascular disease via the inhibition of ROS and a subsequent decrease in the inflammatory response.

\section{Supplementary material}

Click here to view [pdf]

\section{Acknowledgements}

This study was supported by the National Natural Science Foundation of China (\#81100060) and National Key Technology Research and Development Program of the Ministry of Science and Technology of China during of the "12 ${ }^{\text {th }}$ Five-Year Plan" (\#2012BAI05B02).
4. De Torres-Alba F, Gemma D, Armada-Romero E, Rey-Blas JR, Lopez-de-Sa E, Lopez-Sendon JL. Obstructive sleep apnea and coronary artery disease: from pathophysiology to clinical implications. Pulm Med 2013; 2013: 768064, doi: $10.1155 / 2013 / 768064$.

5. Quercioli A, Mach F, Montecucco F. Inflammation accelerates atherosclerotic processes in obstructive sleep apnea syndrome (OSAS). Sleep Breath 2010; 14: 261-269, doi: 10.1007/s11325-010-0338-3.

6. Prabhakar NR, Fields RD, Baker T, Fletcher EC. Intermittent hypoxia: cell to system. Am J Physiol Lung Cell Mol Physiol 2001; 281: L524-L528. 
7. Chin K, Nakamura T, Shimizu K, Mishima M, Nakamura T, Miyasaka M, et al. Effects of nasal continuous positive airway pressure on soluble cell adhesion molecules in patients with obstructive sleep apnea syndrome. Am J Med 2000; 109: 562-567.

8. Dyugovskaya L, Lavie P, Lavie L. Increased adhesion molecules expression and production of reactive oxygen species in leukocytes of sleep apnea patients. Am J Respir Crit Care Med 2002; 165: 934-939, doi: 10.1164/ajrccm. 165.7.2104126.

9. Entzian P, Linnemann K, Schlaak M, Zabel P. Obstructive sleep apnea syndrome and circadian rhythms of hormones and cytokines. Am J Respir Crit Care Med 1996; 153: 1080-1086, doi: 10.1164/ajrccm.153.3.8630548.

10. Ohga E, Nagase $T$, Tomita $T$, Teramoto $S$, Matsuse $T$, Katayama $\mathrm{H}$, et al. Increased levels of circulating ICAM-1, VCAM-1, and L-selectin in obstructive sleep apnea syndrome. J Appl Physiol 1999; 87: 10-14.

11. Vgontzas AN, Papanicolaou DA, Bixler EO, Kales A, Tyson $\mathrm{K}$, Chrousos GP. Elevation of plasma cytokines in disorders of excessive daytime sleepiness: role of sleep disturbance and obesity. J Clin Endocrinol Metab 1997; 82: 1313-1316, doi: 10.1210/jcem.82.5.3950.

12. Vgontzas AN, Papanicolaou DA, Bixler EO, Hopper $K$, Lotsikas A, Lin HM, et al. Sleep apnea and daytime sleepiness and fatigue: relation to visceral obesity, insulin resistance, and hypercytokinemia. J Clin Endocrinol Metab 2000; 85: 1151-1158, doi: 10.1210/jcem.85.3.6484.

13. van Uden P, Kenneth NS, Rocha S. Regulation of hypoxiainducible factor-1alpha by NF-kappaB. Biochem $J$ 2008; 412: 477-484, doi: 10.1042/BJ20080476.

14. Bartels K, Grenz A, Eltzschig HK. Hypoxia and inflammation are two sides of the same coin. Proc Natl Acad Sci U S A 2013; 110: 18351-18352, doi: 10.1073/pnas.1318345110.

15. Ke Q, Costa M. Hypoxia-inducible factor-1 (HIF-1). Mol Pharmacol 2006; 70: 1469-1480, doi: 10.1124/mol.106. 027029.

16. Ryan S, Taylor CT, McNicholas WT. Selective activation of inflammatory pathways by intermittent hypoxia in obstructive sleep apnea syndrome. Circulation 2005; 112: 2660-2667, doi: 10.1161/CIRCULATIONAHA.105.556746.

17. Htoo AK, Greenberg H, Tongia S, Chen G, Henderson T, Wilson D, et al. Activation of nuclear factor kappaB in obstructive sleep apnea: a pathway leading to systemic inflammation. Sleep Breath 2006; 10: 43-50, doi: 10.1007/ s11325-005-0046-6.

18. Yamauchi M, Tamaki S, Tomoda K, Yoshikawa M, Fukuoka A, Makinodan $\mathrm{K}$, et al. Evidence for activation of nuclear factor kappaB in obstructive sleep apnea. Sleep Breath 2006; 10: 189-193, doi: 10.1007/s11325-006-0074-x.

19. Savransky V, Nanayakkara A, Vivero A, Li J, Bevans S, Smith PL, et al. Chronic intermittent hypoxia predisposes to liver injury. Hepatology 2007; 45: 1007-1013, doi: 10.1002/ hep. 21593.

20. Li S, Qian XH, Zhou W, Zhang Y, Feng J, Wan NS, et al. Time-dependent inflammatory factor production and NFkappaB activation in a rodent model of intermittent hypoxia. Swiss Med Wkly 2011; 141: w13309.

21. Yuan G, Nanduri J, Bhasker CR, Semenza GL, Prabhakar NR. $\mathrm{Ca}^{2+} /$ calmodulin kinase-dependent activation of hypoxia inducible factor 1 transcriptional activity in cells subjected to intermittent hypoxia. J Biol Chem 2005; 280: 4321-4328, doi: 10.1074/jbc.M407706200.

22. Fiorentino DF, Bond MW, Mosmann TR. Two types of mouse T helper cell. IV. Th2 clones secrete a factor that inhibits cytokine production by Th1 clones. J Exp Med 1989; 170: 2081-2095.

23. Alberti A, Sarchielli $P$, Gallinella E, Floridi A, Floridi A, Mazzotta G, et al. Plasma cytokine levels in patients with obstructive sleep apnea syndrome: a preliminary study. J Sleep Res 2003; 12: 305-311, doi: 10.1111/j.1365-2869.2003.00361.x.

24. Dyugovskaya L, Lavie P, Lavie L. Phenotypic and functional characterization of blood gammadelta T cells in sleep apnea. Am J Respir Crit Care Med 2003; 168: 242-249, doi: 10.1164/ rccm.200210-12260C.

25. Li Y, Chongsuvivatwong V, Geater A, Liu A. Are biomarker levels a good follow-up tool for evaluating obstructive sleep apnea syndrome treatments? Respiration 2008; 76: 317-323, doi: 10.1159/000119542.

26. Kant S, Swat W, Zhang S, Zhang ZY, Neel BG, Flavell RA, et al. TNF-stimulated MAP kinase activation mediated by a Rho family GTPase signaling pathway. Genes Dev 2011; 25: 2069-2078, doi: 10.1101/gad.17224711.

27. Etienne-Manneville S, Chaverot N, Strosberg AD, Couraud PO. ICAM-1-coupled signaling pathways in astrocytes converge to cyclic AMP response element-binding protein phosphorylation and TNF-alpha secretion. J Immunol 1999; 163: 668-674.

28. Dyugovskaya L, Lavie P, Lavie L. Lymphocyte activation as a possible measure of atherosclerotic risk in patients with sleep apnea. Ann N Y Acad Sci 2005; 1051: 340-350.

29. Liu JN, Zhang JX, Lu G, Qiu Y, Yang D, Yin GY, et al. The effect of oxidative stress in myocardial cell injury in mice exposed to chronic intermittent hypoxia. Chin Med J 2010; 123: 74-78.

30. Phillips SA, Olson EB, Lombard JH, Morgan BJ. Chronic intermittent hypoxia alters NE reactivity and mechanics of skeletal muscle resistance arteries. J Appl Physiol 2006; 100: 1117-1123.

31. Troncoso Brindeiro CM, da Silva AQ, Allahdadi KJ, Youngblood V, Kanagy NL. Reactive oxygen species contribute to sleep apnea-induced hypertension in rats. Am J Physiol Heart Circ Physiol 2007; 293: H2971-H2976, doi: 10.1152/ ajpheart.00219.2007. 